Article

\title{
Modeling Autonomous Decision-Making on Energy and Environmental Management Using Petri-Net: The Case Study of a Community in Bandung, Indonesia
}

\author{
Niken Prilandita *, Benjamin McLellan and Tetsuo Tezuka \\ Graduate School of Energy Science, Kyoto University, Yoshida-Honmachi, Sakyo-ku, Kyoto 606-8501, Japan; \\ b-mclellan@energy.kyoto-u.ac.jp (B.M.); tezuka@energy.kyoto-u.ac.jp (T.T.) \\ * Correspondence: nikenpri@sappk.itb.ac.id; Tel.: +81-75-753-4739; Fax: +81-75-753-9189 \\ Academic Editor: Palmiro Poltronieri \\ Received: 28 December 2015; Accepted: 5 April 2016; Published: 14 April 2016
}

\begin{abstract}
Autonomous decision-making in this study is defined as the process where decision-makers have the freedom and ability to find problems, select goals, and make decisions for achieving the selected problems/goals by themselves. Autonomous behavior is considered significant for achieving decision implementation, especially in the context of energy and environmental management, where multiple stakeholders are involved and each stakeholder holds valuable local information for making decisions. This paper aims to build a structured process in modeling the autonomous decision-making. A practical decision-making process in waste-to-energy conversion activities in a community in Bandung, Indonesia, is selected as a case study. The decision-making process here is considered as a discrete event system, which is then represented as a Petri-net model. First, the decision-making process in the case study is decomposed into discrete events or decision-making stages, and the stakeholders' properties in each stage are extracted from the case study. Second, several stakeholder properties that indicate autonomous behavior are identified as autonomous properties. Third, presented is a method to develop the decision-making process as a Petri-net model. The model is utilized for identifying the critical points for verifying the performance of the derived Petri-net.
\end{abstract}

Keywords: autonomy; decision-making; Petri-net; energy; environmental; community; Indonesia

\section{Introduction}

The recent global agenda and technological challenges for creating a more sustainable environment have encouraged countries around the world to gradually shift towards sustainable energy transitions. Upon the new global agreement of Sustainable Development Goals, every country is now highly anticipated to direct their efforts towards realizing a more sustainable energy system and environment [1]. From the technology side, the emergence of new technologies, such as smart grids and source-centered renewable energies, have expanded the potential and requirements of energy generation and management in ways that have not been available previously. These facts suggest that the energy system is likely to become more distributed and localized, thus the decision-making and policy-making process in the energy sector should be adjusted to follow this future tendency [2].

Most decisions made on energy and environmental management affect a large number of people and, thus, are of public interest. Decision-making in this sector usually becomes complicated since various interests need to be accommodated in the process. Moreover, once a consensus has been successfully reached, it does not guarantee successful implementation. Various decision-making approaches for reaching an easy consensus, as well as for achieving successful implementation, have been proposed. Two common approaches in decision-making are with the centralized and the 
decentralized approaches [3,4]. The quest of balancing between the centralized and the decentralized systems for decision-making is often an issue in organizational management. Easy access to information with the advancement of information technology, the internet, and other means today, have made the decision-making style in organizations lean towards a more decentralized style $[5,6]$. However, this approach may not be entirely applicable for cases in energy and environmental management that occur in the public domain.

This study puts more focus on autonomy in decision-making processes regardless of whether they are conducted under a centralized or a decentralized system. Two ways of understanding the concept of autonomy are considered here. Firstly, autonomy in the political or public administration field, which is often seen as one of the traits of a more decentralized system [4]. Secondly, as understood in the current study, autonomy can be considered as a property of persons regardless of the systemic context [7-9]. Therefore, we argue that autonomy can exist in both centralized and decentralized approaches because autonomy is the property of each decision-maker.

The hypothesis of this study is that decisions made autonomously are more likely to achieve successful outcomes. Autonomy in making decisions is believed to be related to an increase in quality of life. Research from neuroscience has found that actively making decisions can boost pleasure and increase the decision-makers' happiness, satisfaction, and perceived control [10]. Furthermore, high levels of happiness and satisfaction are causal influences on success and achievement, not the other way around [11]. Simply stated, if a decision-maker has made an autonomous decision, without being coerced or forced, it is considered more likely that the decision-maker will achieve the decision goal and benefit from that.

Normatively, stakeholders' autonomy in making decisions is important, though its important role in decision-making may not been objectively examined [7]. The fact that we have not found studies that objectively examined the role of autonomy in decision-making in energy-environmental management showed that this theme has to date been insufficiently examined. We argue that the recent global agenda and technological advances in the energy-environmental sector (e.g., smart-grid technologies, decentralized energy, and market liberalization) expect decision-makers to become more autonomous. This situation has created the necessity to develop a framework that can represent and identify the role of stakeholders' autonomy in the decision-making process. Such a framework would consist of several elements employed for specific tasks, and is the purpose of the current research. This paper discusses one of the important elements of the framework, a model that aims to represent, analyze, and simulate the autonomous decision-making process.

The autonomous decision-making model in this paper is developed as a discrete event system, and this paper presents the method to build such a model. The decision-making process is decomposed into discrete events that we call decision-making stages. Afterwards, the properties of stakeholders involved in each stage are identified; thus, the concept of a discrete event system for autonomous decision-making is established. Petri-net is utilized to represent the discrete event system of the autonomous decision-making process. Each decision-making stage, the stakeholders' properties, and the state after decisions are made; corresponding to a small Petri-net model consisting of a few transitions and places. The autonomous decision-making model is constructed by combining all of these small Petri-net models of each event/stage. As an addition, we conducted analysis of the Petri-net model's behavior for identifying the stages which are indispensable for an autonomous decision-making system. These stages are called the critical points in the autonomous decision-making process.

\section{The Definition of Autonomous Decision-Making}

This section explains the definition of autonomous decision-making. The term, autonomous decision-making is defined by dissecting it into the root words comprising it, which are "autonomy" and "decision-making". The development of the concept of autonomy as a political and personal property is historically explained, followed by a brief explanation on various scopes of the 
decision-making process, and various types of energy decision-making. Based on this information, we construct the definition of autonomous decision-making used in this study.

\subsection{The Concept of Autonomy}

The definition of autonomy has been through several changes throughout the course of history. As mentioned above, there are at least two different concepts of autonomy explained in this paper. Autonomy originated from the Greek words "auto" which means self, and "nomos" which means law. This concept was firstly coined referring to the city states in ancient Greece that were self-governing. Originally, autonomy was defined in a political manner, which was the right of the states (or city-states, in that instance) to administer their own affairs [9]. In the context of public administration management, territorial or local autonomy is the result of a decentralization process [12]. In the Indonesian context for example, the Law of Decentralization number 22/1999, was the beginning of the country's journey towards a more decentralized political structure. This law has since become the legal basis for providing more autonomy to local governments in making decisions regarding their own territory and environment. The spirit of the law has had a side effect, however, in that it caused the Indonesian people to gain greater awareness of autonomy, knowing that they had more freedom in choosing among options. This has promoted decision-making processes to be performed more autonomously in various levels of society's hierarchical structure, including at the lower authority levels, such as villages and sub-districts [13]. Looking at this fact, the term autonomy in Indonesia has gradually become understood not only as the property of a state or territory, but also as a personal trait.

One of the most important moments in the history of the concept of autonomy was when the definition of autonomy was transformed from the property of a state in the ancient Greek era, into a property of persons during the Renaissance era $[7,8]$. Since then, the concept of autonomy has been understood in both ways. However, autonomy in the majority of contemporary works is seen as a property of persons, or personal autonomy [7]. Although the concept of autonomy mainly revolves around these two definitions, the dimensions of autonomy are understood in many different ways, depending on which field of study is viewing it. Mackenzie, for example, defined three dimensions of autonomy, namely self-determination, self-governance, and self-authorization [14]. Other studies focus on the self-directedness and resoluteness dimensions of autonomy [9]. Meanwhile, the computer science and information technology fields view the ability to continuously learn or self-learning traits in the emergence of autonomous machines or artificial intelligence as one of the most important characteristics of autonomy [15].

\subsection{Decision-Making Process}

The definition of decision-making has been long established, and since decision-making is understood as a process of making decisions, then the definitions mostly evolved on the scope of the process. There are two predominately different views in decision theory regarding the extent of the decision-making scope. Firstly, decision-making is defined as a process started by identifying problems or goals, and ended after a decision has been made. One of the main supporters of this concept was Herbert Simon (1960) [16]. Later, Huber (1980) expanded the concept of decision-making by defining it as "the process through which a course of action is taken" [17], and the process by which the decision is implemented is considered as part of the problem-solving process. Most of the studies that defined the decision-making process came from the field of organizational management. Meanwhile when decisions need to be made in the public domain, the decision-making process is often regarded as the whole cycle from problem identification up to decision implementation and evaluation, and then feeding-back to problem identification. This is known as a generic decision cycle [18], or a planning process [19]. An example of a decision-making cycle is presented in Figure 1. In this study, we investigate the decision-making process extended to the implementation stages. 


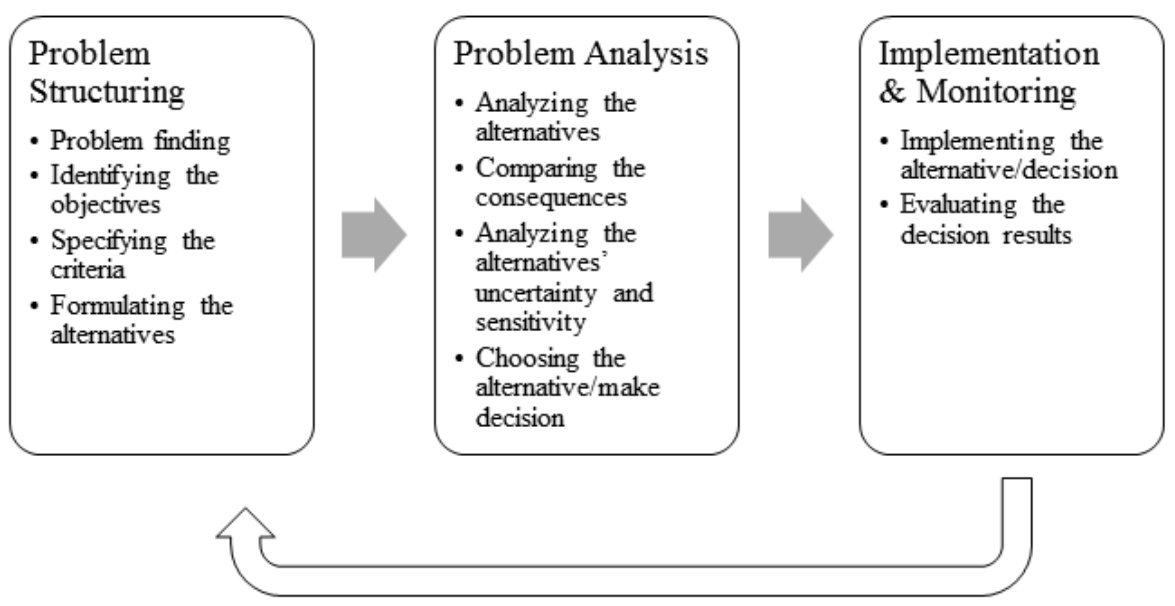

Figure 1. Example of a decision-making cycle $[18,19]$.

\subsection{Energy-Environmental Decision-Making at Various Stakeholder Levels}

The following section explains decision-making in energy and environment by various stakeholders, such as national government, local government (provincial/city/regency governments, and formal agencies/bodies within these local governments), community, household and individual (households and individuals are considered as a single decision-maker), and non-governmental institutions (i.e., international and local NGOs, business or private sector stakeholders, media, experts and academicians). As mentioned earlier, decision-making in energy and environmental management often becomes complex because it occurs in the public domain and, therefore, various stakeholders are involved in it. According to Sexton, et al. [20], the main stakeholders that are usually involved in environment-related decision-making are national governments, regional or local government bodies, business associations, environmental advocacy groups, community or neighborhood groups, and affected or interested individuals. The relationships between these stakeholders can be classified into two types of relationship, which are vertical (hierarchical) and horizontal (parallel) relationships with each other [21,22]. Decision-making for individual stakeholders and groups of stakeholders is influenced both by the structure of relationships and the characteristics of the individual stakeholders.

Energy related decision-making and policy-making (We use the phrase "energy (and environmental) decision-making and policy-making" or "decision-making in energy sector" interchangeably in this paper because the research object is related with both energy and environmental sector.) at the national level tends to occur in a top-down manner, following the hierarchical structure of the country's institutions. In the UK, for example, energy decision-making functions have historically been performed mainly by the central government and large corporations in the private sector. This situation began to change after the Localism Bill was stipulated in 2010 aiming to shift decision-making power from central governments to individuals, communities, and local government [23,24]. Another example is from a developing country, Indonesia, where for more than two decades since the first national energy policy was introduced in 1981, the key strategic energy decisions and policies are made centrally by the national government [25]. The role of local government in the energy sector was recognized after the promulgation of the Energy Act in 2007. The act mandates each local government to formulate its own local energy masterplan, based on the targets outlined by the national energy masterplan.

Recent experiences from both countries have shown that the local authorities are mandated and expected to have more capacity in energy decision-making functions. The long period of centralized energy decision-making experience in both countries has created a great challenge for the local authorities to pick up the task. Lack of capacity of the local government with regards to energy planning, and limited guidelines on how to formulate the masterplan itself, are some of the challenges faced by the locals. Despite the limited capacity and experience, local governments around the world have developed various energy-environmental measures and local action plans, as a 
form of participation in global initiatives such as the International Council for Local Environmental Initiatives (ICLEI) and the Climate Alliance [26]. Aside from having a mandate to implement energy-environmental measures at the local level, local authorities are also expected to involve and nurture the community or grassroots levels in local energy initiatives [27].

Energy decision-making functions at the community level have been empirically observed in North America [28-30]. Most of the decisions and measures taken are on climate change mitigation planning, considered as the re-emergence of the energy planning efforts which increased after the oil crisis in the 1970s, but later declined in the 1980s due to lower energy prices [28]. Although the number of local actions for energy measures in USA were increased after 2006, all of the decision-making processes identified were initially developed at the municipality level first [28]. The municipalities then involved the community in their plans to reduce community-wide energy use and GHG emissions. Although similar, the Canadian experience with its community energy management or community energy planning program is slightly different from what happened in the USA. Observations of the Community Energy Plans (CEPs) that emerged during 2003-2007 [29,30] have shown the potential of community roles in formulating action plans specifically related to energy efficiency, energy conservation, and application of renewable energies [30]. However, since CEP is part of a broader commitment of the municipalities on forming local action plans for GHG reduction, the content of the CEP is often written in accordance to what the municipality or municipal council needs [29]. These practices are somewhat different from what was conceived by Jaccard, et al. [31] as community energy management.

The practices of energy related decision-making at the community level is also evident in European countries, such as in the UK and Germany [27,32,33]. Often referred to as grassroots initiatives [27,34] or community (renewable) energy [33,35], it is defined as projects where communities exhibit a high degree of ownership and control, and collectively benefit from the outcomes [35]. The term community in this literature is relatively broad, referring to a group of people who share the same geographical location (neighborhood communities) or the same interest (non-governmental organizations) [33]. The recent practices of community energy in Europe are gradually shifting as part of socio-political movements from the grassroots level [27] and, thus, they are more likely to be considered as bottom-up initiatives when compared to the CEPs in North America.

Energy decision-making at the individual level is traditionally studied as a part of consumer behavior studies which view the individual as the energy customer or end-user [36,37]. Individuals as consumers make everyday decisions related to energy; therefore, they are becoming the target of various energy measures [37], such as the behavior change programs in energy consumption and energy technology adoption [38]. The high potential of new energy systems and technologies such as renewable energy systems and smart grids have shifted the focus of individual energy decision-making. In the light of these technologies, individuals' energy decisions are not only shaped by the energy system and policy, but can also shape the system [39]. The social foundation of smart grids consists of "decentralized socio-technical networks that underpin the electricity consumption of groups of consumers who are increasingly becoming autonomous" [40]. However, for effective technology adoption, it is suggested to no longer view the individual solely as a consumer of energy, but also as a citizen, part of a community or society [37].

From the research related with energy decision-making above, it is found that energy decision-making functions occur at various stakeholder levels, and the decisions made by one stakeholder may affect others in the total energy system. The challenge of shifting towards a more localized and distributed energy system creates a need for every stakeholder not only to actively participate in energy decision-making, but also to become more autonomous.

\subsection{Definition of Autonomous Decision-Making}

In this research, we put more focus on autonomy as the property of persons, not as a property of the system or environment. This study considers that each decision-maker is seen as an autonomous 
system, or in other words, autonomy is a property of each stakeholder who participates in the decision-making process. This means that every decision-maker or stakeholder has their own goal to achieve and has the autonomy to decide by themselves. Thus, as mentioned earlier, this study views that autonomy can exist in both centralized and decentralized approaches.

In light of this, we define the autonomous decision-making as the process where decision-makers have the freedom and ability to find problems, select goals, and make decisions for achieving the selected problems/goals by themselves in a responsible manner based on available information. It follows that persons having the ability to self-determine, self-govern, show self-control, and self-learning are persons who exhibit autonomous behavior. The definition for each autonomous behavior used in this paper is presented in Table A1 in the Appendix.

\section{Methodology for Modeling an Autonomous Decision-Making Process}

The aim of this study is to develop the autonomous decision-making model for the energy and environmental management process by using Petri-net. For this aim, an energy-environmental management project in Indonesian community (Rukun Warga) is selected as a case study. The steps performed for modeling in this paper are: (1) case selection and data collection; (2) decomposing the decision-making process and extraction of the stakeholders' properties; (3) identification of stakeholders' autonomous properties; and (4) modeling the decision-making process from the observed case using Petri-net and analysis of the model.

\subsection{Case Study Selection and Data Collection}

This paper undertook one decision-making process as a case study to be modeled, and there is a strong indication to select this particular case. The selected case study was included and investigated along with other five community decision-making processes in our previous work [41]. These cases were, in turn, selected from a broader set of around 20 case studies. The five cases were selected due to their success in project implementation and the availability of detailed documentation and information. Among the five cases, the community presented in this study was considered to have utilized both centralized (top-down) and decentralized (bottom-up) decision-making approaches. Since we argued that autonomous decision-making can occur under both approaches, by selecting this case we can investigate and model autonomous decision-making under both approaches using the same case. In addition to that, by using the same case study which exhibits two different decision-making approaches over a period of time, the behavior change and improved capability of the community in making decision were observed.

The model developed here is based on a case study of a practical decision-making process for a waste management system project in a community in Bandung City, Indonesia. The waste management technique utilized in the community project is a bio-digester installation to transform household waste to energy (biogas). This case was selected because a considerable number of stakeholders were involved in the activities with relatively even inputs to the project. Various stakeholders' involvement in a project is a rare occasion, especially when almost all stakeholders can contribute relatively evenly in the project. This situation occurred because the project developed in two phases. The first phase started as one project and then changed to another project after the first went through a stagnant phase. The second phase achieved quite a successful outcome and is still in operation at the time of writing. The stakeholders that were involved in each phase are different, which is one reason why there were various stakeholder contributions. This unique situation is considered useful for understanding the possible outcomes from various stakeholders' engagement when the project changed course.

A thorough data collection is necessary for understanding the case study well. Information about the community activities and decision-making process were collected using secondary and primary sources. Various secondary records used were project reports, academic reports, journal articles, newspaper articles, and web-based articles. Interviews, informal discussions, observation, and demonstration of the biogas installation were also undertaken during site visits. The primary sources 
interviewed are the chief of the community, the former community chief, bio-digester operators, and the recycling center operator.

\subsection{Decomposing the Decision-Making Process and Extraction of the Stakeholders' Properties}

The decomposition of the case study is important for constructing the autonomous decision-making model as a discrete event system. There are two steps involved in this decomposition, which yield two major results that become the foundation of the discrete event system for modeling autonomous decision-making. Firstly, the community decision-making process is decomposed into decision-making stages. Secondly, the properties of each stakeholder involved in each stage are identified. Utilizing the framework developed in our previous work [41], the decision-making process is decomposed. Modified from Simon [16], Huber [17], and Petrie [18], the framework consists of four important phases, namely: (1) problem finding; (2) knowledge and information; (3) consensus building; and (4) decision and implementation (see Figure 2). The points or questions in each phase function as guidance in decomposing decision-making stages and identifying the stakeholders' involvement.

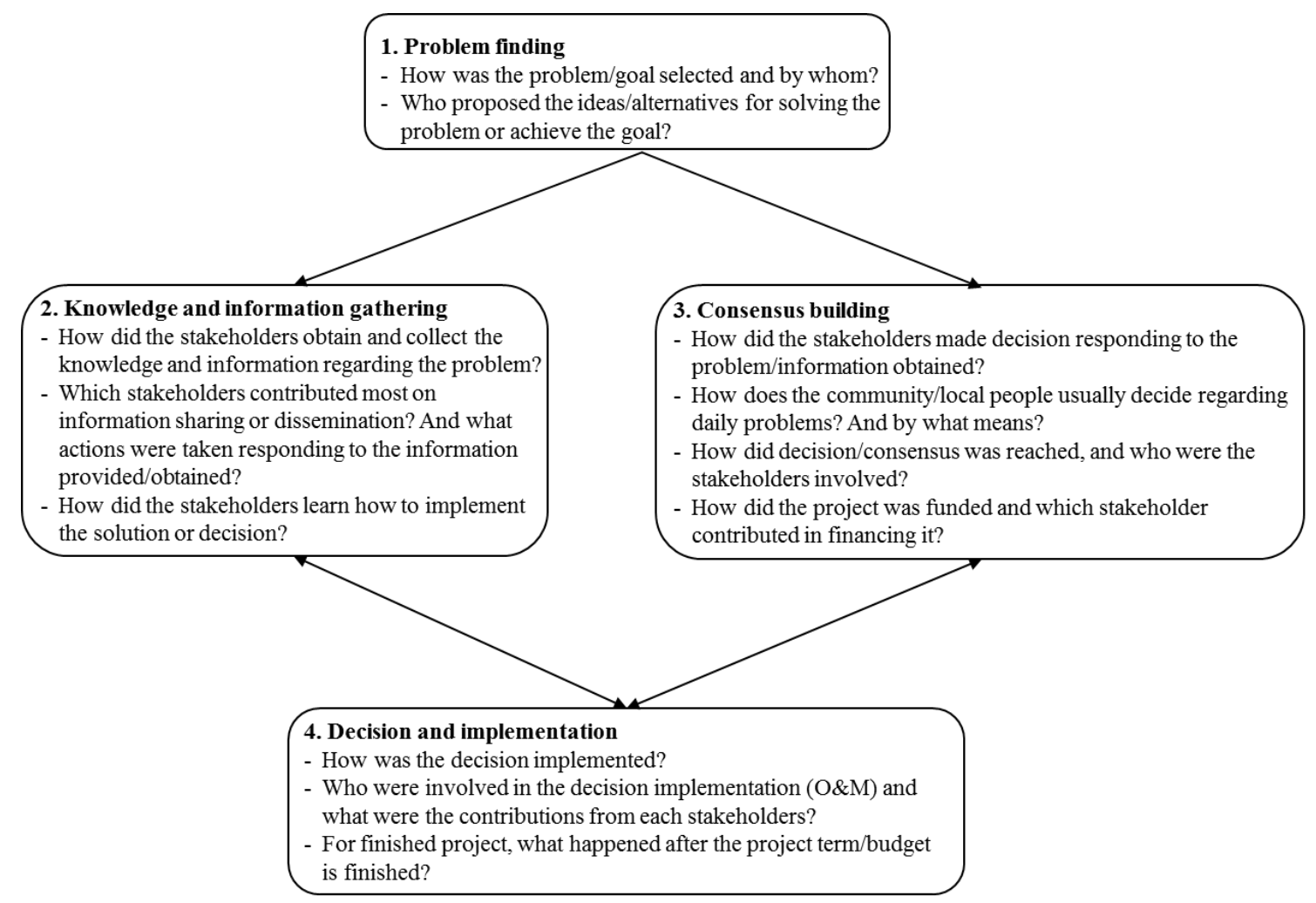

Figure 2. The decision-making decomposition framework [41].

The procedure for extraction of stakeholders' general properties was performed based on our previous work which utilized five case studies of community energy-environmental projects, of which the present case study was one [41]. The five different cases of community projects selected (from a set of around 20) exhibit various types of decision-making processes, ranging from centralized to decentralized approaches. All of the five cases were considered as successful in reaching the project goals. From analysis of these successful cases, the role and properties of the stakeholders' are extracted by utilizing the framework in Figure 2, with the properties and the framework development itself based on the decision-making literature. 


\subsection{Identifying the Stakeholders' Autonomous Properties}

The structured method for identifying the stakeholders' autonomous properties from the stakeholders' general properties is explained here. The list of stakeholders' general properties which contributed to the success of the community project was derived from a thorough literature review into decision-making processes, cross-checked with successful case studies. In order to determine which of these properties are aligned with autonomy in decision-making, a further analysis was undertaken. The decision-making process, as a whole, is considered to be autonomous decision-making if the stakeholders in the system are making decisions autonomously. In other words, the stakeholders need to exhibit an autonomous behavior. Therefore, the stakeholders' autonomous properties are identified by cross-comparing the stakeholders' general properties with elements of autonomous behavior.

The cross-comparison process was performed qualitatively using content analysis of the autonomous behaviors and stakeholders' properties definitions. The stakeholders' general properties are identified in the previous step, while the elements of autonomous behavior are identified in Section 2, namely: (1) self-governance; (2) self-control; (3) self-learning; and (4) self-determination. Upon defining each stakeholders' property and autonomous behavior, each property is examined. Those which comply with at least one definition of autonomous behavior are identified as stakeholders' autonomous properties. Utilizing this method, the stakeholders' autonomous properties can be objectively identified.

\subsection{Developing and Analyzing the Autonomous Decision-Making Model Using Petri-Net}

The method for constructing the autonomous decision-making process using Petri-net is presented in this section. The justification of Petri-net utilization is explained, followed by the Petri-net history and its utilization. Afterwards, a brief explanation of a standard Petri-net model. The autonomous decision-making model developed in this paper is built as a discrete event system by compiling the results from previous steps, which are the decision stages and the stakeholders' properties. The method to represents the discrete events into a Petri-net model is also explained in this section.

In this paper, we consider the decision-making process as a system built upon discrete events which perform and interact with each other sequentially and in parallel. Energy-environmental decision-making is of public interest, therefore the decision-making involves many and various stakeholders. In our research, the stakeholders are autonomous. They are being shaped by, and can also shape, the system. Therefore, an interrelated bi-directional connection between stakeholders and the decision-making process is expected. Petri-net has an advantage of representing the model in two-ways: graphically and mathematically. Therefore, we consider that Petri-net is a suitable tool to represent the complexity of multiple autonomous stakeholders in energy-environmental decision-making. Moreover, the utilization of Petri-net enables a simple simulation of autonomous decision-making model to be performed further.

Petri-net is one of the tools often utilized for modeling a discrete event system, and nowadays its application has been employed on a very broad field of study, including decision-making. The history of Petri-net is established by its development by Carl Adam Petri in 1962. Petri-net is useful for modeling the flow of information and control in systems, especially those which exhibit asynchronous and concurrent events [42-44]. Petri-net is commonly applied to model various kinds of dynamic discrete-event systems such as computer networks, manufacturing plants, communication systems, logistic networks, and command and control systems [45]. In recent years, the utilization of Petri-net has reached far beyond computer science and manufacturing studies. For example, Petri-net has been used to model decision-making processes in a legal case [46] and modeling the story plot for games [47,48]. In the energy-environmental field, several studies have employed Petri-net in modeling: a more energy efficient machine tool [49], multisource energy conversion systems [50], energy management system for autonomous micro-grids [51], municipal waste management [52], and environmental effects of biofuel utilization [53]. The advantage of utilizing Petri-net in this study is that it can describe objectively a decision-making process with multi-stakeholder involvement. 
A standard Petri-net consists of $\mathrm{P}, \mathrm{T}, \mathrm{I}, \mathrm{O}, \mu$ (places, transitions, inputs, outputs, marking/token). In detail, $\mathrm{P}$ is a finite set of places, which are represented by circles; $\mathrm{T}$ is a finite set of transitions, which are represented by rectangles/bars; I is an input function which represents connection from $\mathrm{P}$ to $\mathrm{T}$; $\mathrm{O}$ is an output function which represents a connection from $\mathrm{T}$ to $\mathrm{P}$; and $\mu$ is the initial marking which is represented by a small dot called a token [54].

In order to transform the discrete events of autonomous decision-making into Petri-net accordingly, the results from previous steps are compiled. First, the result from decomposing the decision-making process are the decision stages. These decision-making stages, which are considered as discrete events, are transformed into "transitions" in the Petri-net model, whereas the result from the autonomous properties extraction is the stakeholders' properties. The state or the combinations of the stakeholders' properties, are represented as "places". Likewise, the results or outputs from each event/stage are also represented as "places". The relationship between the state and the stages are represented with inbound and outbound arcs. In short, the decision-making stages can be transformed into the Petri-net by:

1. Describing the state of affairs or a condition experienced by the stakeholder as a Place (P).

2. Describing the decision-making process, or event, or action conducted by the stakeholder as a Transition (T).

3. Describing the relationship of Place(s) and Transition(s) and the movement of the token $(\mu)$ with inbound and outbound arcs.

The token moves from one place to another by "firing" through a transition. A place has a token if a particular stakeholders' condition or property is satisfied, thus firing the transition. The existence or the absence of the condition is the key factor that determines whether a transition in the Petri-net is enabled or not.

The decision-making model is constructed by combining all of the transitions and places representing the decision-making stages into one Petri-net model. For simplification purposes, several decision stages are represented as simple Petri-net models, which are drawn hierarchically in another layer under the main model. These lower layers of Petri-net models do not affect the purpose of the whole model, which tries to show the relationship between stakeholders' autonomous properties in each decision-making stage and decision outcomes.

The utilization of Petri-net to describe the decision-making process made the autonomous part of the decision-making more prominent and easier to be identified. Therefore, we can identify the critical points in the decision-making process, where the existence or absence of autonomous properties will lead to a different decision or achieve different outcomes. The performance of autonomous properties in the success of the decision-making is going to be evaluated by analyzing the combinations of the conditions resulting from the simulation.

\section{Results}

This section presents the results obtained from each method aforementioned. A brief description of the selected case study is presented prior to the results from decomposing the case study decision-making process into stages. The stakeholders' autonomous properties are identified afterwards. Later on, the development and analysis of the decision-making model using Petri-net are explained.

\subsection{Overview of the Case Study}

As described earlier, the case study project had two phases, and each phases is briefly explained here. The initial project was called a Community-based Basic Infrastructure Improvement Program (CBIIP), with the final goal to improve the sanitation situation in the community. The case study consists of two related projects, which are a composting center and bio-digester installation. The bio-digester 
installation project was an improvement to an existing composting project in the RW 11 community (RW are often identified by number. RW 11 means it is the 11th community to exist in the particular village). This community, inhabited by 3000 people, or roughly 800 households, is one of the low-income slum areas in Bandung. It is one of the densest districts in the city. Recognizing the need for improvement of community life, CBIIP was initiated by the Ministry of Public Works in the Bandung Branch with assistance from the Bandung City government in 1996. Focusing on economic, social, and environmental aspects, one of the projects conducted was the construction of a composting center located in RW 11 to improve the poor sanitation and waste situation [55]. After the project term was finished and the budget terminated, the composting center operation became stagnant, and was then replaced by a bio-digester installation.

The second project, a biogas production project in the form of a bio-methane digester installation, was initiated by the community in collaboration with academicians, the private sector, and community-based organizations ( $\mathrm{CBO}$ ). After the composting system was not as successful as planned, especially in terms of profit, it was terminated around 2009-2010. However, views on waste and garbage in the RW 11 community had changed. They maintained the waste segregation activities, and the women's organization (My Darling) began selling plastic waste and tried to reuse it for handicrafts. Moreover, the existing $\mathrm{CBO}$ tried to seek financial support by submitting proposals to international and national non-governmental organizations (NGOs) [56]. Eventually, with assistance and consultation from academic scholars, the Environmental Agency and a local NGO, and financial help from the local bank, the composting system was changed to the bio-methane system, which produces biogas for households and liquid fertilizer.

One recent study about the biogas production in this community has been conducted thoroughly [57]. The outcomes from the biogas production project were studied from socio-economic perspectives. It was found that the biogas production at RW 11 is currently not economically feasible due to limited market reach for the bio-slurry products. Meanwhile from the social point of view, the study identified that the community was relatively accepting of the project despite a mix of responses found among RW 11 community members. It can be concluded that this pilot project in biogas production is still operating because of the social acceptance factors rather than economic factors.

\subsection{The Decision-Making Stages and Stakeholders' Properties}

The decomposition of the decision-making process resulted into two major outputs. The first output are the decision-making stages, and the second are the stakeholders' general properties. These outputs are the foundation in establishing an autonomous decision-making model as a discrete event system. The case history and other related information obtained from various sources are analyzed qualitatively to decompose the decision-making process of the case study into decision stages. Utilizing the framework in Figure 2, we decomposed the decision-making process of the biogas production project in RW 11 into six stages, which are:

1. Find or define the problem

2. Design the solution alternatives

3. Agreement/consensus building

4. Implementation and construction of the Waste Management System (WMS)

5. Management $(\mathrm{O}$ and $\mathrm{M})$

6. Termination of the project

Even though the framework suggested four major phases, the number of stages drawn in the Petri-net model may vary and, thereby, be more than four. The biogas production project in RW 11 has been established for a long time, therefore, it has been gone through the stages of "management" and "project termination". Moreover, the project has been regenerated into another project, which is still running. Depending on the case study, the decomposition of the decision-making process may 
result in various numbers of stages. These stages are represented in the Petri-net model as transitions. The relationships between each transition are drawn by combining it with the stakeholders' properties.

As mentioned in Section 3.2, the stakeholders' properties are extracted from the successful case studies by applying the same framework (Figure 2) and based on literature on various decision-making processes. These properties were taken from various energy-environmental decision-making studies, as presented in Table A2 in the Appendix. This process resulted in the stakeholders' general properties, listed in Table 1 . These extracted properties are considered to be those which contributed to successful community decision-making implementation. The stakeholders' general properties are further examined using autonomous behavior elements in Section 2 to identify the stakeholders' autonomous properties.

Table 1. Stakeholders' general properties.

\begin{tabular}{clcl}
\hline \multicolumn{4}{c}{ Stakeholders' General Properties } \\
\hline 1 & Self-control & 11 & Trust \\
2 & Initiative & 12 & Interaction \\
3 & Self-learning & 13 & Collaboration \\
4 & Motivation & 14 & Openness \\
5 & Ability to organize & 15 & Commitment \\
6 & Leadership & 16 & Local culture \\
7 & Self-governance & 17 & Networking ability \\
8 & Ability to collect and & 18 & Creativity \\
9 & understand information & 19 & Innovativeness \\
10 & Communication ability & 20 & Proximity \\
\hline
\end{tabular}

\subsection{The Stakeholders' Autonomous Properties}

Identification of the stakeholders' autonomous properties is one of the important process conducted in this paper. The properties extracted in previous step are general stakeholder properties that contributed to the success of the project goal. These properties are cross-compared with the autonomous behaviors mentioned in Section 2. Among the 20 general properties listed above, three of them are already included as autonomous behaviors (self-control, self-learning, and self-governance). The remaining 17 properties were cross-checked with the autonomous behaviors.

The method for identifying stakeholders' autonomous properties explained in Section 3.3 requires each autonomous behavior and the general properties listed in Table 1 to be clearly defined. From these definitions (see Appendix, Tables A1 and A2), the stakeholders' general properties are objectively identified as to which autonomous behavior they exhibit (if any). The results of this cross-comparison are presented in Table 2.

From Table 2, eleven out of seventeen properties are considered as exhibiting stakeholders' autonomous behavior. The other six are not marked as autonomous behavior of the stakeholder, for at least two reasons. First, they are not a property of persons or individuals. The properties, such as local culture, trust, and proximity are categorized as a system or environment property. Therefore, even though they exhibit some traits of autonomy, they are not included as stakeholder properties. Second, the properties of creativity and innovativeness, by definition, are not regarded as corresponding with the autonomy definition or dimensions. 
Table 2. Extraction of Stakeholders' autonomous properties.

\begin{tabular}{cccccc}
\hline \multirow{2}{*}{ No } & $\begin{array}{c}\text { General } \\
\text { Decision-Making } \\
\text { Property }\end{array}$ & Self-Governance & Self-Control & Self-Learning & Self-Determination \\
\cline { 3 - 6 } & Initiative & $\mathrm{X}$ & $\mathrm{X}$ & $\mathrm{X}$ & $\mathrm{O}$ \\
\hline 1 & Motivation & $\mathrm{X}$ & $\mathrm{X}$ & $\mathrm{X}$ & $\mathrm{O}$ \\
\hline 2 & Ability to organize & $\mathrm{O}$ & $\mathrm{O}$ & $\mathrm{X}$ & $\mathrm{X}$ \\
\hline 3 & Leadership & $\mathrm{O}$ & $\mathrm{O}$ & $\mathrm{X}$ & $\mathrm{X}$ \\
\hline 4 & Ability to collect and & $\mathrm{X}$ & $\mathrm{X}$ & $\mathrm{O}$ & $\mathrm{X}$ \\
\hline 5 & understand information & $\mathrm{O}$ & $\mathrm{X}$ & $\mathrm{X}$ & $\mathrm{X}$ \\
\hline 6 & Communication ability & $\mathrm{X}$ & $\mathrm{O}$ & $\mathrm{X}$ & $\mathrm{O}$ \\
\hline 7 & Responsibility & $\mathrm{X}$ & $\mathrm{X}$ & $\mathrm{X}$ & $\mathrm{X}$ \\
\hline 8 & Trust & $\mathrm{X}$ & $\mathrm{X}$ & $\mathrm{O}$ & $\mathrm{X}$ \\
\hline 9 & Interaction & $\mathrm{X}$ & $\mathrm{X}$ & $\mathrm{O}$ & $\mathrm{X}$ \\
\hline 10 & Collaboration & $\mathrm{X}$ & $\mathrm{X}$ & $\mathrm{X}$ & $\mathrm{O}$ \\
\hline 11 & Openness & $\mathrm{X}$ & $\mathrm{O}$ & $\mathrm{X}$ & $\mathrm{X}$ \\
\hline 12 & Commitment & $\mathrm{X}$ & $\mathrm{X}$ & $\mathrm{X}$ & $\mathrm{X}$ \\
\hline 13 & Local culture & $\mathrm{X}$ & $\mathrm{X}$ & $\mathrm{O}$ & $\mathrm{X}$ \\
\hline 14 & Networking ability & $\mathrm{X}$ & $\mathrm{X}$ & $\mathrm{X}$ & $\mathrm{X}$ \\
\hline 15 & Creativity & $\mathrm{X}$ & $\mathrm{X}$ & $\mathrm{X}$ & \\
\hline 16 & Innovativeness & Proximity & & & $\mathrm{X}$ \\
\hline 17 & & & & $\mathrm{X}$ & \\
\hline & & & & & \\
\hline
\end{tabular}

After correlating these properties with the autonomy dimensions, selected properties are further classified into seven points based on definitional similarity, and they are as follows:

1. Motivation, initiative; selected because the decision-makers need to have motivation or initiative, or ability to think by themselves in order to be considered as autonomous.

2. Leadership, ability to organize; selected because autonomy also requires self-governance and self-control. In order to have the ability to govern or organize themselves, the decision-makers need to have some level of leadership and ability to coordinate and communicate their goal with their subordinates or members.

3. Self-learning, ability to manage information; selected because an autonomous decision-maker needs to have the willingness and ability to learn, to manage and collect information, and to understand the information necessary to make decisions.

4. Interaction between the community members; one of the results of the analysis conducted on the five cases was that the interaction among community leaders and members has an important role in reaching a consensus or decision, as well as in decision implementation, and sustaining the operation and maintenance of the project. A decision that is reached through group interaction performs better when compared to a decision reached by a group of people that does not interact at all [58].

5. Networking and collaboration between stakeholders; this property is linked with the previous property. We differentiate it because, in this property, the community (leaders and members) is considered as one stakeholder. The networking and collaboration between the community and other stakeholders outside the community, such as government agencies, officials, local NGOs, private sectors, and others, was seen in the five cases and contributed to the success of the project.

6. Persuasion and negotiation ability; this property is closely related with the leadership level of the stakeholder. This property was also very useful in reaching a consensus or decision, especially 
when the project involved multiple stakeholders. This property is found predominantly in the cases where the initiative does not come from governments.

7. Responsibility and commitment; this property is especially important when the decision is ready to be implemented. In order for the project to be constructed, each stakeholder involved needs to be responsible for their duty and commit to the decision that has been made.

\subsection{The Petri-Net Model}

The autonomous decision-making model, which in this paper is regarded as a discrete event system, is represented using Petri-net. The principal process of modeling the decision-making into Petri-net can be described as follows. Each stage of the decision-making in Section 4.2 is transformed into transition for the Petri-net model. For graphical purpose, we provide two version of Petri-net graphs. The simplified Petri-net diagram for this case study is presented in Figure 3, meanwhile the complete Petri-net graph using Yasper is presented in Figure A1 in the Appendix.

The conditions for each stakeholder involved are given at the beginning of the net, and are not changed during the course of the process. There are three subnets added (for detail see Appendix, Figure A2-A4). Each subnet is designed for one autonomous property, namely the Motivation Subnet (T1), the Leadership Subnet (T2), and the ability to manage information, shortened as the Information Subnet (T3). The reason behind the subnets' creation is because the model will be simulated by changing the number of stakeholders involved and changing the combination of their properties. Therefore, it is important to show the process of how each stakeholder becomes autonomous or non-autonomous in detail. However, we realized that this process can make the whole decision-making process model more visually complex. Therefore, we added several subnets in the Petri-net model, hence, making it a hierarchical model. The subnets show the process of every stakeholder in becoming autonomous or non-autonomous. Autonomous stakeholders will have a token in the corresponding places, whereas those who do not have autonomous properties will have no token. The other reason is because the content of these hierarchical transitions are fluid, depending on how many stakeholders are involved. This makes it inefficient to draw directly on the primary layer.

The results from these hierarchical transitions from the subnets are shown on the primary layer as one single place, which is a simplification of the number of places corresponding to each stakeholder involved (in Figure 3, these are designated by blue coloring, hereafter they are called "blue" places). If the number of stakeholders is more than one, then each blue place consists of a combination of stakeholders' conditions. This simplification is purely for graphical purposes. These blue places are drawn as several single places in the complete version of the Petri-net model. The example given in Figure A1 of the Appendix shows that if there are five autonomous stakeholders involved in the decision-making process, this would result in each of the hierarchical transitions (T1, T2, and T3) producing five tokens in each of the corresponding places. Therefore, each blue place in primary layer (P2, P3, and P4) actually consists of five single places with a token in it. For simulation purposes, it is not possible to simply put five tokens in each of $\mathrm{P} 2, \mathrm{P} 3$, and $\mathrm{P} 4$. This is because at later transitions (T6 and T8), the rules are specifically differentiated based on the stakeholder types. Decision-making processes may require certain specific stakeholders to make an autonomous decision-in this case a token from these stakeholders will be compulsory. In addition to this, the specific direction that a decision takes may be designated by which, or how many, other stakeholders have autonomous properties (a token, in this case).

In Figure 3, there are three variations of transition. First, is the standard transition, which is marked by a black box. Second, the orange diamond-shape transition, which represents an XOR transition. An XOR transition consumes one token from one of its input places and produces a token in one of its output places. This means that this transition can be fired if there is at least one token in one of its input places. The third transition is a hierarchical transition (T1-T3). As mentioned before, the Petri-net model in this paper is a hierarchical one, meaning there is another process or another set 
of Petri-net models under the primary layer. A detail explanation on the variations of transitions with the corresponding decision type used in this paper is presented in Table 3.

There are three other important elements of the Petri-net model shown in Figure 3, namely the inbound arcs, outbound arcs, and tokens. The inbound and outbound arcs between places and transitions show the direction of token movement. In addition, they also show the relationship between places and transitions. Since places represent the conditions needing to be fulfilled for firing the transitions, it is easy to identify what kind of conditions are required for an action or event to occur. The bidirectional arc represents a simplification of a situation in which whenever a transition is fired, then the transition will produce a token in the output place and also put the token back in the input place. The legend for the Petri-net in Figure 3 is presented in Table 4.

The Petri-net developed in this paper shows that the discrete event system consists of decision-making stages and the role of stakeholders involved in a decision-making process can be objectively and logically modeled. Utilizing the procedures explained above, other decision-making cases can also be represented using Petri-net. Although the model might be different in detail, the decision-making stages are relatively similar.

Table 3. Type of transitions with its corresponding decisions type.

\begin{tabular}{cl}
\hline Type of Transition & \multicolumn{1}{c}{ Type of Decision } \\
\hline Standard transition & $\begin{array}{l}\text { Used if the condition(s) to reach a particular action/decision is unnegotiable, or if the } \\
\text { number of states resulted from a particular action/decision are definite. }\end{array}$ \\
\hline XOR transition & $\begin{array}{l}\text { Used if there are two or more states that possible as inputs or outputs of the particular } \\
\text { action/decision. This type of transition is usually applied to decisions that branches } \\
\text { subject to certain conditions. }\end{array}$ \\
\hline Hierarchical transition & $\begin{array}{l}\text { Used as a representative of a sub-layer in the Petri-net. The sub-layer contains another set } \\
\text { of transitions-places which is deliberately hidden to simplify the main Petri-net model. }\end{array}$ \\
\hline
\end{tabular}

Table 4. Legend for places and transitions in the Petri-net model.

\begin{tabular}{cccc}
\hline Place & Description & Transition & Description \\
\hline P1: & Waste and sanitation problem situation & T1: & Motivation subnet \\
\hline P2: & Set of stakeholders' motivation level & T2: & Information subnet \\
\hline P3: & $\begin{array}{c}\text { Set of stakeholders' ability to manage } \\
\text { information level }\end{array}$ & T3: & Leadership subnet \\
\hline P4: & Set of stakeholders' leadership level & T4: & Problem finding process \\
\hline P5: & Problem is defined & T5: & Designing alternatives process \\
\hline P6: & Alternatives are designed & T6: & Decision-making \\
\hline P7: & $\begin{array}{c}\text { WMS technique is selected } \\
\text { (decision is made) }\end{array}$ & T7: & Construction of WMS \\
\hline P8: & $\begin{array}{c}\text { WMS is constructed } \\
\text { (decision is implemented) }\end{array}$ & T8: & Operation \& Maintenance \\
\hline P9: & Waste is reduced & T9: & Termination of the project \\
\hline P10: & Project stopped & & \\
\hline P11: & Project continued & & \\
\hline
\end{tabular}




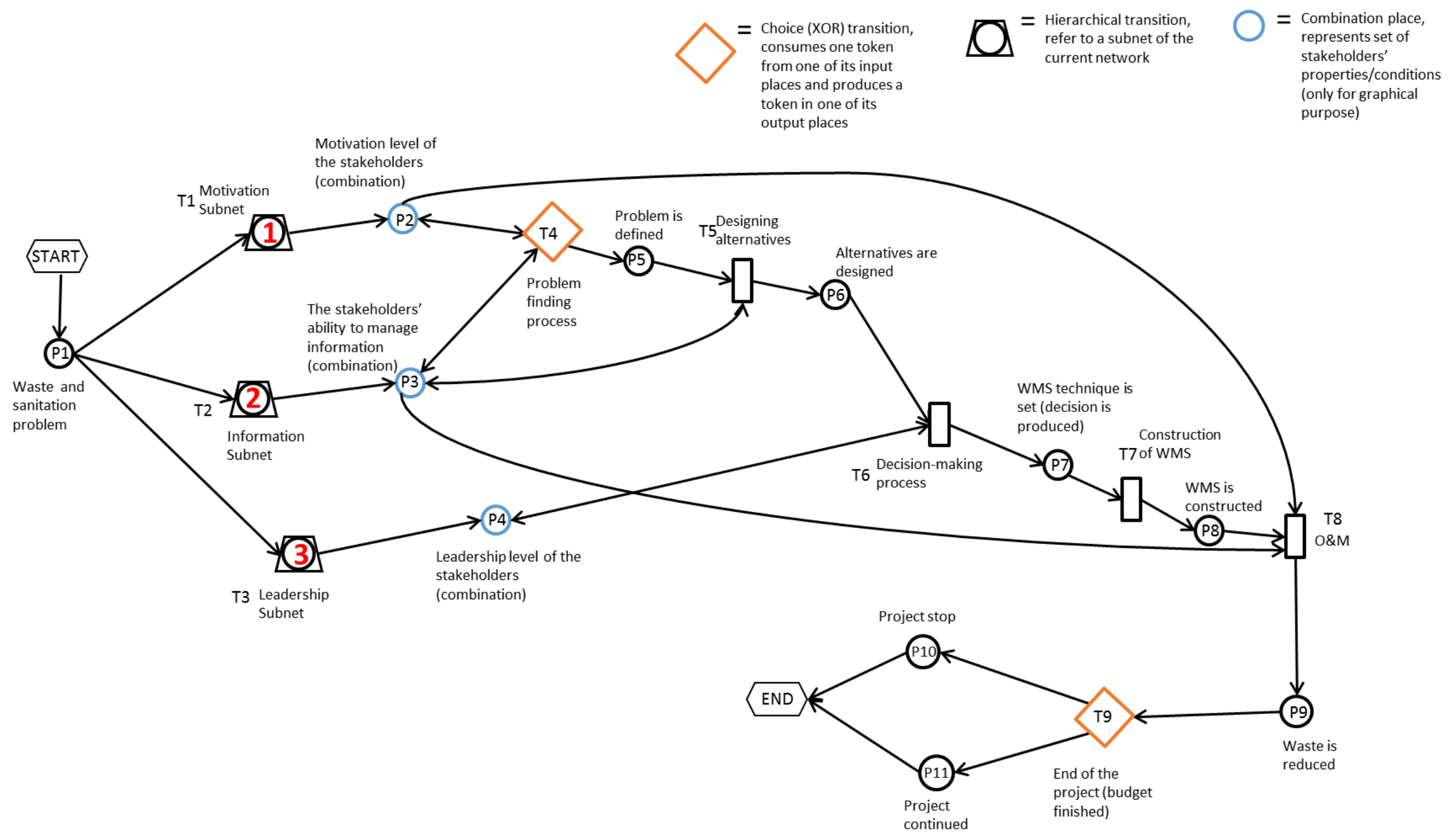

Figure 3. Hierarchical Petri-net (simplified) describing the decision-making process of a WMS case study. 


\section{Analysis and Discussions}

Two main steps were performed through the methods explained in this paper. First is the method to decompose the community decision-making process into discrete events. This process resulted into two outputs, which are the decision-making stages (Section 4.2) and the stakeholders' autonomous properties (Section 4.3). The second step is the method to build the discrete event system in the form of the Petri-net model, which generalizes the decision-making in a case of energy and environmental management (Section 4.4).

The decomposition process produces decision-making stages and the stakeholders' autonomous properties. The decision-making stages are performed utilizing the framework in Figure 2. As a result, six decision-making stages are obtained; namely, problem definition, alternatives design, agreement or consensus building, implementation and construction, management, and project termination, whereas the stakeholders' properties are identified by qualitatively cross-comparing the stakeholders' general properties with the autonomous behaviors. There are seven autonomous properties identified here; namely, (1) motivation and initiative; (2) leadership and ability to organize; (3) self-learning or the ability to manage information, (4) interaction; (5) networking and collaboration; (6) persuasion and negotiation ability; and (7) responsibility and commitment. Among these, properties (4) and (5) are considered as more a property of groups of people, meaning they exist if there are at least two types of stakeholders involved in the decision-making, whereas the other properties belong to an individual stakeholder.

The results from the decomposition process are then represented by Petri-net. The model is constructed by combining the decision-making stages that already converted into transitions and places. Analysis of the Petri-net provide a further understanding that there are several transitions that would yield different outcomes if the conditions at the blue places are changed. These transitions are identified as critical points, which are identified from Petri-net graph in Figure 3.

As discussed in Section 4.4, a blue place contains the result from the hierarchical transitions and each blue place can represent more than one "standard" place. A token in one of the sub-places contained in a blue place represents the particular stakeholders' autonomous properties and it will not be changed during the course of the simulation. For example, if a stakeholder is set since the beginning as not having motivation properties, then it will continue to lack motivation until the end of the model or the termination of the model. A critical point in this study refers to a certain transition in the Petri-net model that is influenced by the conditions set in the blue places, which have particular influence on autonomy. From the model, the critical points identified in this decision-making process are:

1. Problem finding process (T4). At this critical point, there are two determining properties, which resulted from motivation subnet (T1) and information management capability (T2). T4 fires if there is at least one token in one of its input places (P2 and P3). This means that at this stage, any stakeholder, regardless the type, can contribute in finding the problem as long they have high motivation or strong leadership.

2. Designing alternatives (T5), fires depending on the property of information management capability (T2). T5 fires if there is a token in P5 and there is at least one token in P3. This means that in order to design decision alternatives, at least one stakeholder must have the capability to manage information.

3. Decision-making process or consensus-building process (T6), which is determined by the property of leadership level (T3). T6 fires if there is a token in P6 and at least one token in $\mathrm{P} 4$. This means that in order to reach a decision or a consensus together, at least one stakeholder needs to have strong leadership. The output of this transition is differentiated by the specific stakeholders' conditions. 
4. Operation and maintenance phase (T8), is determined by all three properties of: leadership level (P4), motivation level (P2), and information management capability (P3). Basically, T8 fires if there is a combination between the properties of several stakeholders together. This means that collaboration, networking, and interaction between stakeholders plays an important role in this Operation and Maintenance stage. However, since the leadership property (P4) is already given in T6, therefore there is no need to connect T8 with the inbound arc from P4. The result of T8 will be differentiated based on the properties from blue places based on types and properties of stakeholders.

5. Termination of the project (T9), determining property: result from the $\mathrm{O}$ and $\mathrm{M}$ phase (T8). The outputs from the previous transition (T8) are differentiated based on the stakeholder types and properties. In the simulation, the rule will be imposed on T9 as to whether to produce a token for P10 or P11, based on the token condition in P9. For example, if the token produced from T8 shows a condition of autonomous local people (community leaders or interested individuals), then the project will be more likely to go beyond project termination, and therefore T9 will produce a token in P11. Since T9 is an XOR transition, the firing of T9 can only be produced in one of P10 or P11.

Among these critical points, the first two points (T4 and T5) determine whether the process will reach a decision or fail to reach a decision. The latter three points (T6, T8, and T9) determine the variety of success levels in achieving the project goal. Meanwhile T7 is not identified as a critical point because the transition only depends on one input place.

The Petri-net model in this paper represents the decision-making process as it occurred in community case studies. The common traits of community decision-making should not be neglected. For example, in a community, if a certain problem exists and a stakeholder proposes some solution alternatives but the remaining stakeholders are not able to reach a consensus or decision, then the whole decision-making process fails/stagnates and the problem will persist. This means that, for solving the same problem, the decision-making process needs to be started from the beginning again. In the simulation, this trait will be represented by the instant termination of the model simulation every time a transition is not fired.

The critical points in this paper are identified by developing the Petri-net model which resulted from carefully decomposing the case study. Therefore, the most important part is decomposing the case's story into decision-making stages, which can only be performed if the case study or project history is well understood. This made the data collection procedure holds an important role in understanding the context under which the decision was taken. Although complete information might be available in the form of reports and secondary records, direct field visits and observations are highly recommended to obtain a thorough understanding of the targeted community, and also to avoid bias from previous researchers. Another important point is the selection of principal informants to be interviewed. It is best to interview stakeholders that are involved directly at the beginning of the project even though they might already be very old or have already stepped down from their position if the project has been conducted for a number of years.

The method explained throughout this paper comprises of decomposing the community decision-making process, extraction of the stakeholders' autonomous properties, and modeling the autonomous decision-making process. The results of these steps are complemented by the results obtained from various literature and data collection. The structured method utilized in this paper can be summarized in Figure 4 below. 


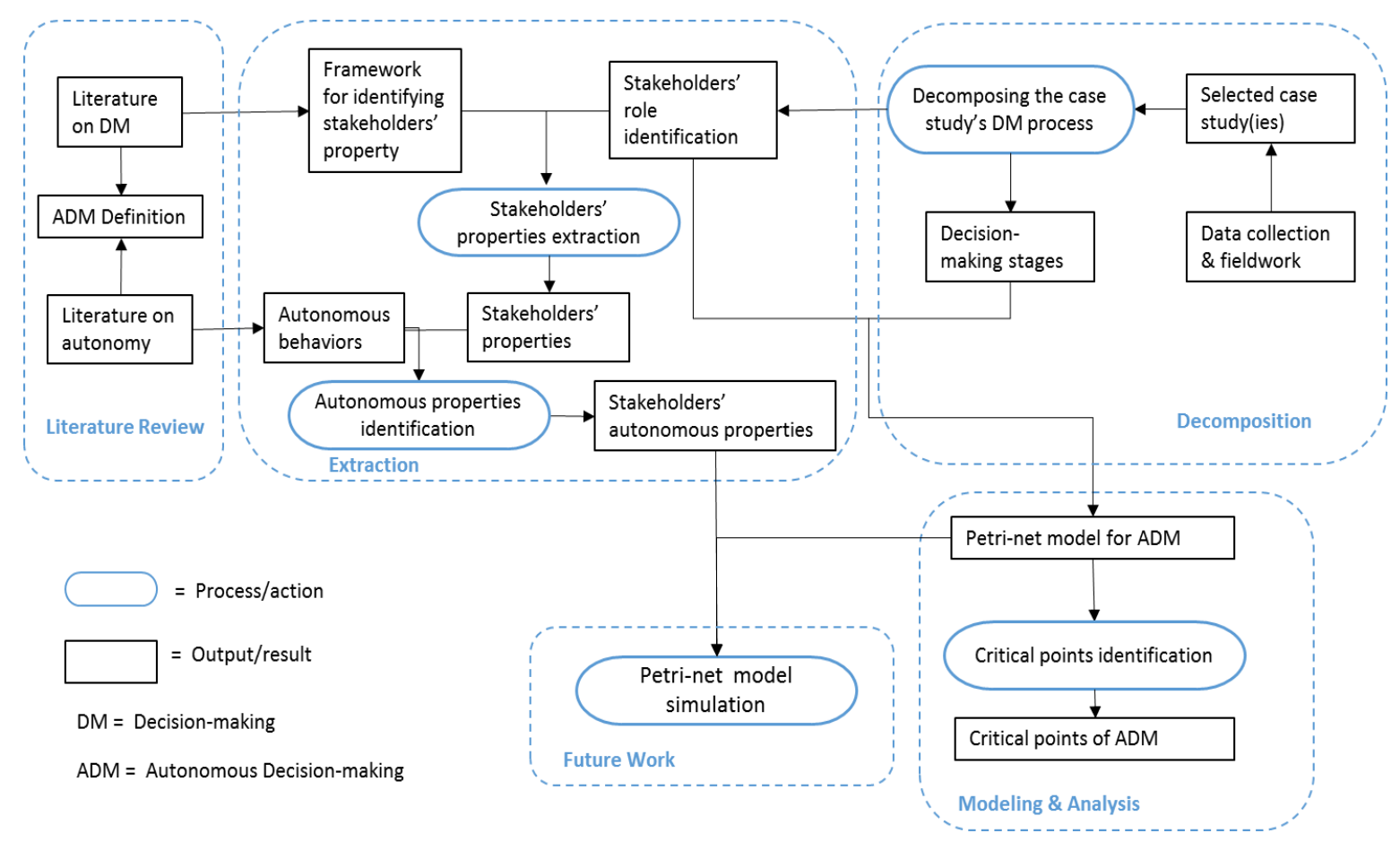

Figure 4. General method for developing autonomous decision-making model.

\section{Conclusions}

This paper presents a method to build an autonomous decision-making model, which is considered to be important within the development of decentralized generation and demand-centered projects in energy and environmental beneficiation. However, the approach is generalizable to other fields and case studies beyond that presented here. The specific Petri-net must be designed given the understanding of the stakeholders and project elements involved in decision making, which is performed by decomposing a decision-making process into discrete events or decision-making stages as shown in Figure 4. Using Petri-net as a tool, the decision-making stages are transformed into a set of place-transitions or simple Petri-net models, and these small models are compiled to construct the autonomous decision-making model. The utilization of Petri-net to represent decision-making models helps the decision-making process to be analyzed objectively and important stages of autonomous decision-making are prominently shown. These important stages are identified as critical points of autonomous decision-making. A critical point is influenced by the stakeholders' properties and determines the output of the model, or whether the model can reach the end of the network or not.

The results of this paper are going to be further employed for simulations based on the Petri-net model. The utilization of Petri-net in building the autonomous decision-making model is considered as one of the effective ways to perform the model simulation in the future study. Some of the stakeholders' autonomous properties identified above such as motivation, leadership, and ability to manage information, are going to be assigned deterministically to each stakeholder involved in the decision-making process and various outcomes from the simulations will be observed in order to identify the key conditions suitable for successfully achieving goals.

Acknowledgments: The authors are grateful for the comments and suggestions from three anonymous reviewers. The first author would like to extend her gratitude to the Ministry of Education, Culture, Sports, Science and Technology (MEXT), Japan, for supporting this study.

Author Contributions: The manuscript is prepared by Niken Prilandita, under the supervision of Tetsuo Tezuka and Benjamin McLellan, who assisted in co-authoring and improving paper.

Conflicts of Interest: The authors declare no conflict of interest. 


\section{Appendix}

Table A1 below listed the behaviors or characteristics that commonly associated with autonomous individual, or even used to define the concept of autonomy. The second column shows that these behaviors appeared or even mentioned as a prerequisite for succeeding a decision implementation based on various literature in decision-making, especially in the energy and environmental sector. The third column contain general definition of each behavior, which are useful for the cross-comparing process in Section 4.3 .

Table A1. Definition of elements of autonomous behavior.

\begin{tabular}{clc}
\hline Autonomous Behavior & \multicolumn{1}{c}{ Definition } & Mentioned in \\
\hline \multirow{3}{*}{ Self-governance } & $\begin{array}{l}\text { Governance refers to the processes of interaction and } \\
\text { decision-making among the actors involved in a collective } \\
\text { problem that lead to the creation, reinforcement, or } \\
\text { reproduction of social norms and institutions [59]. Therefore, } \\
\text { self-governance defined as the capability of an individual or } \\
\text { group to develop their own way to establish the governance } \\
\text { and running it without intervention. }\end{array}$ \\
\hline Self-control & $\begin{array}{l}\text { Refers to a set of processes that enable individuals to guide } \\
\text { their goal directed activities over time and across changing } \\
\text { contexts [60]. Often used interchangeably with } \\
\text { self-regulation [61]. }\end{array}$ \\
\hline Self-learning & $\begin{array}{l}\text { The capability to perform the act of learning by oneself. } \\
\text { Learning here defined as the acquisition of knowledge and/or } \\
\text { skills that serve as an enduring platform for adaptive } \\
\text { development and to comprehend and navigate novel } \\
\text { problems [61]. }\end{array}$ \\
\hline Self-determination & $\begin{array}{l}\text { The capacity to choose and to have those choices, rather than } \\
\text { reinforcement contingencies, drives, or any other forces or } \\
\text { pressures, be the determinants of one's actions. } \\
\text { Self-determination often involves controlling one's } \\
\text { environment or one's outcomes, but it may also involve } \\
\text { choosing to give up control [64]. }\end{array}$ \\
\hline
\end{tabular}

Table A2 below are the observed stakeholders' properties existed in the successful cases of community project in energy-environmental management. The second column shows that these properties appeared or even mentioned as a prerequisite for succeeding a decision implementation based on various literature in decision-making, especially in the energy and environmental sector. The third column contain general definition of each properties, which are useful for the cross-comparing process in Section 4.3.

Table A2. Definition of stakeholders' general properties.

\begin{tabular}{ccl}
\hline Properties & Mentioned in & \multicolumn{1}{c}{ Definition } \\
\hline Initiative & {$[4]$} & $\begin{array}{l}\text { Behavior characterized by self-starting nature, proactive approach, and } \\
\text { by being persistent in overcoming difficulties that arise in the pursuit of } \\
\text { a goal [61]. }\end{array}$ \\
\hline Motivation & {$[3,4]$} & $\begin{array}{l}\text { Refers to the set of psychological processes governing the direction, } \\
\text { intensity, and persistence of actions that are not due solely to } \\
\text { overwhelming environmental demands that coerce or force action [61]. }\end{array}$ \\
\hline
\end{tabular}


Table A2. Cont.

\begin{tabular}{|c|c|c|}
\hline Properties & Mentioned in & Definition \\
\hline Initiative & [4] & $\begin{array}{l}\text { Behavior characterized by self-starting nature, proactive approach, and } \\
\text { by being persistent in overcoming difficulties that arise in the pursuit of } \\
\text { a goal [61]. }\end{array}$ \\
\hline Motivation & {$[3,4]$} & $\begin{array}{l}\text { Refers to the set of psychological processes governing the direction, } \\
\text { intensity, and persistence of actions that are not due solely to } \\
\text { overwhelming environmental demands that coerce or force action [61]. }\end{array}$ \\
\hline $\begin{array}{l}\text { Ability to } \\
\text { organize }\end{array}$ & [4] & $\begin{array}{l}\text { Capacity to coordinate, manage, facilitate, a particular object/tasks } \\
\text { among group of people to reach a certain goal [61]. }\end{array}$ \\
\hline \multirow[t]{2}{*}{ Leadership } & \multirow[t]{2}{*}[66,67]{} & $\begin{array}{l}\text { A set of role behaviors by individuals in the context of the group or } \\
\text { organization to which they belong. }\end{array}$ \\
\hline & & $\begin{array}{l}\text { The exercise of influence over others by utilizing various bases of social } \\
\text { power, tactics, and so on in order to elicit the group members' } \\
\text { compliance with certain norms and their commitment to achieve the } \\
\text { group's objectives [61]. }\end{array}$ \\
\hline $\begin{array}{l}\text { Ability to } \\
\text { collect and } \\
\text { understand } \\
\text { information }\end{array}$ & {$[3]$} & $\begin{array}{l}\text { Capacity to collect and understand information without help from } \\
\text { other parties. }\end{array}$ \\
\hline $\begin{array}{l}\text { Communication } \\
\text { ability }\end{array}$ & {$[4]$} & $\begin{array}{l}\text { Capacity to exchange in exchange information, form understandings, } \\
\text { coordinate activities, exercise influence, socialize, and generate and } \\
\text { maintain systems of beliefs, symbols, and values among members of } \\
\text { institution/organizations [61]. }\end{array}$ \\
\hline Responsibility & {$[68,69]$} & $\begin{array}{l}\text { An attribute that an adult person is duty-bound to undertake [70]. } \\
\text { In environmental behavior, it defined as an individual sense of } \\
\text { obligation or duty to take measures against environmental } \\
\text { degradation [71]. }\end{array}$ \\
\hline Trust & [3] & $\begin{array}{l}\text { A generalized expectancy held by an individual or group that the word, } \\
\text { promise, verbal, or written statement of another individual or group } \\
\text { can be relied on [61]. }\end{array}$ \\
\hline Interaction & [72-74] & $\begin{array}{l}\text { A particular kinds of social relationship that are different from, but } \\
\text { constitutive of, groups, organizations, and networks. Interaction occurs } \\
\text { when two or more participants are in each other's perceptual range and } \\
\text { orient to each other through their action and activity [75]. }\end{array}$ \\
\hline Collaboration & {$[76,77]$} & $\begin{array}{l}\text { Collective action or effort performed by a group of people to solve } \\
\text { problem or adjust environments in order to discover new mutually } \\
\text { beneficial options [77]. }\end{array}$ \\
\hline Openness & [4] & $\begin{array}{l}\text { Referred as transparency to access information within organization, } \\
\text { institution, or society [78] }\end{array}$ \\
\hline Commitment & {$[79,80]$} & $\begin{array}{l}\text { Referred as the level of identification with, and attachment and loyalty } \\
\text { to, an organization, an occupation, or some other feature of work [61]. }\end{array}$ \\
\hline Local culture & {$[61]$} & $\begin{array}{l}\text { Some shared set of characteristics in common to a particular group of } \\
\text { people [61]. }\end{array}$ \\
\hline $\begin{array}{l}\text { Networking } \\
\text { ability }\end{array}$ & {$[73,81]$} & $\begin{array}{l}\text { Capacity to perform a process of contacting and being contacted by } \\
\text { people in one's social or technical/professional world and maintaining } \\
\text { these linkages and relationships [61]. }\end{array}$ \\
\hline Creativity & {$[4,82,83]$} & $\begin{array}{l}\text { The generation of ideas or products that are both novel and appropriate } \\
\text { (correct, useful, valuable, or meaningful) [61]. }\end{array}$ \\
\hline Innovativeness & {$[83,84]$} & $\begin{array}{l}\text { The degree to which an individual is relatively earlier in adopting new } \\
\text { ideas than the other members of a system [85]. }\end{array}$ \\
\hline Proximity & {$[86,87]$} & $\begin{array}{l}\text { Referred to the spatial distance or familiarity of a certain object or } \\
\text { problem to a person or group of person. }\end{array}$ \\
\hline
\end{tabular}




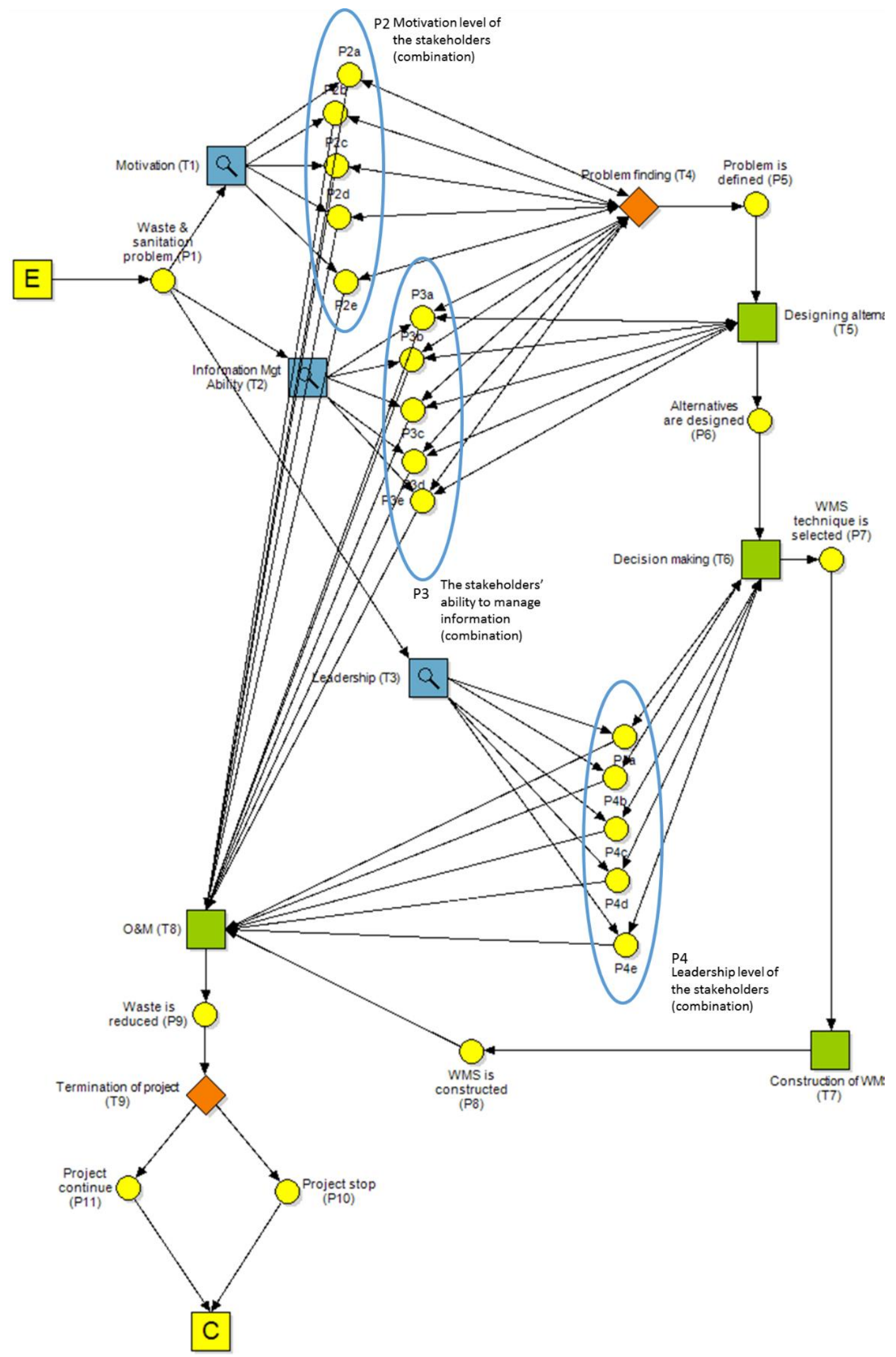

Figure A1. The Petri-net model drawn using Yasper (no simplification). 


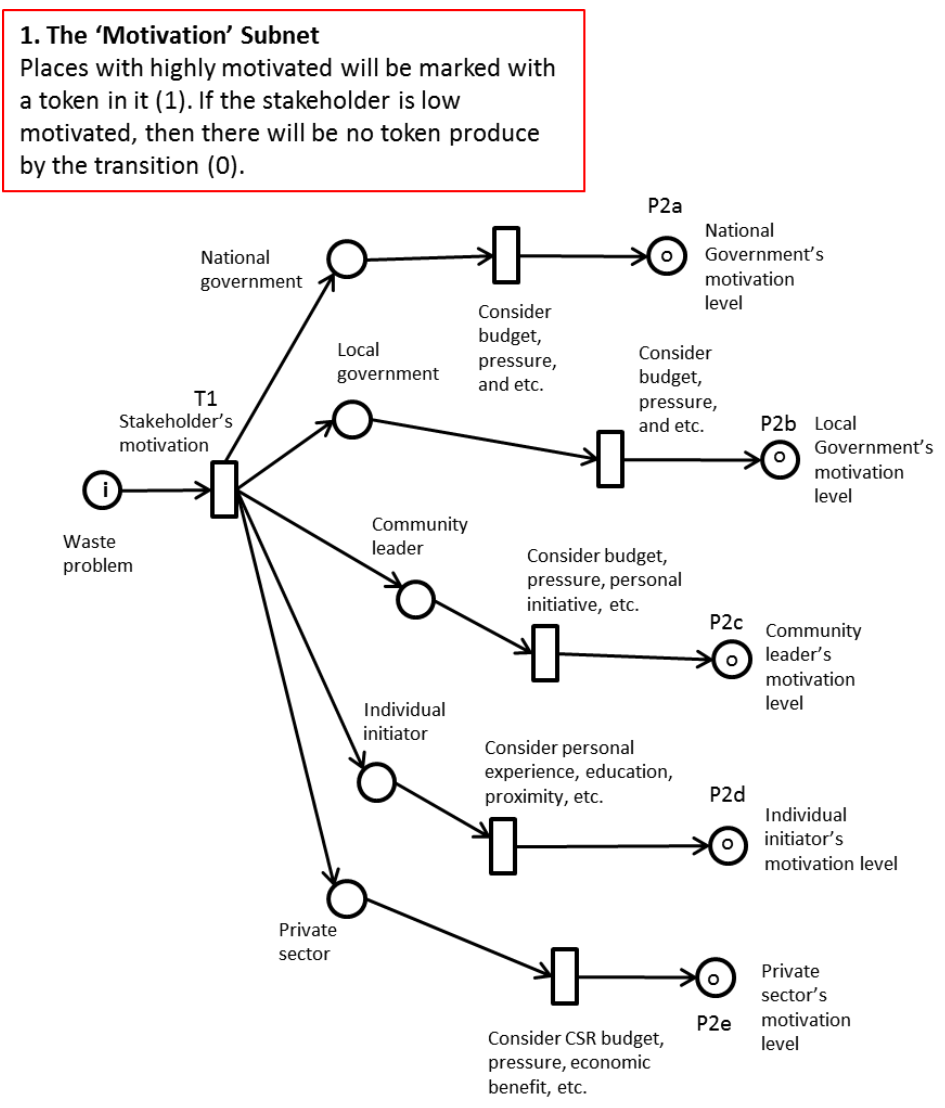

Figure A2. The "Motivation" Subnet.

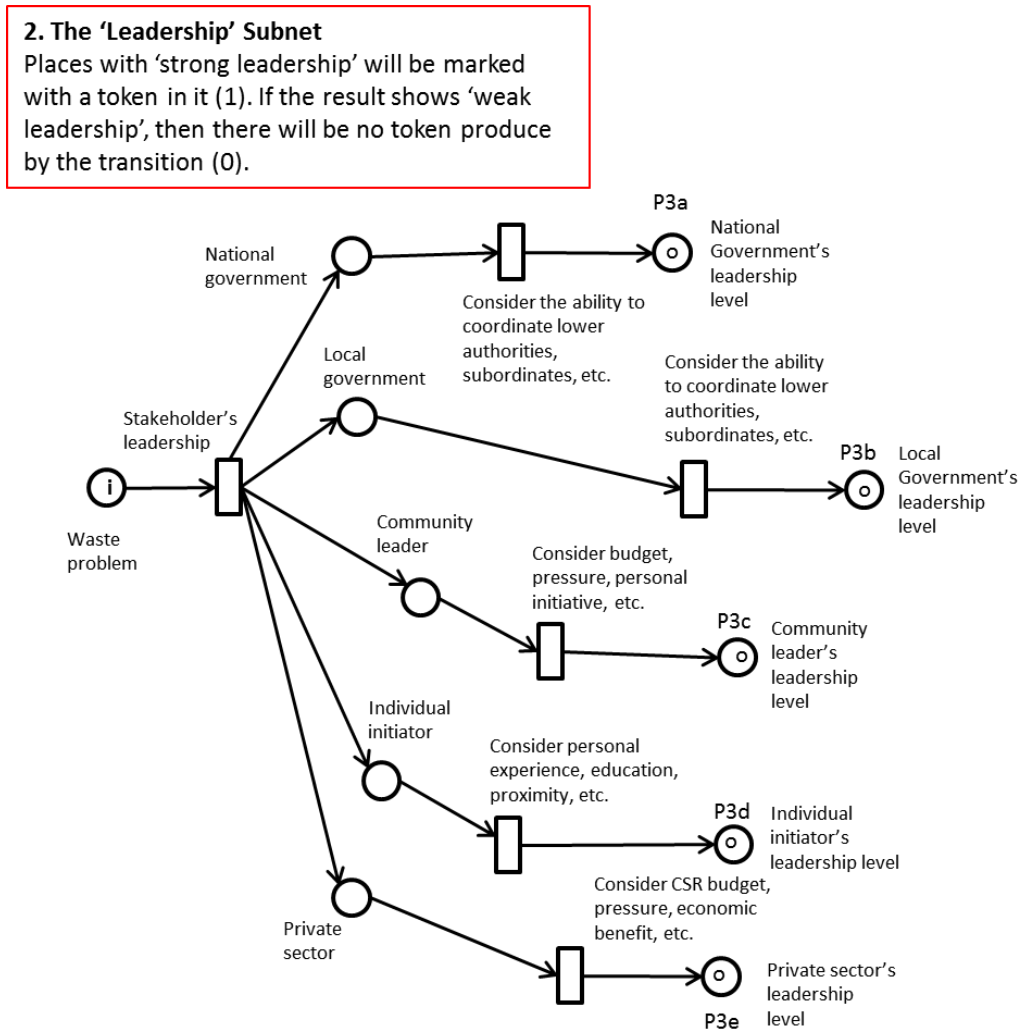

Figure A3. The "Leadership" Subnet. 


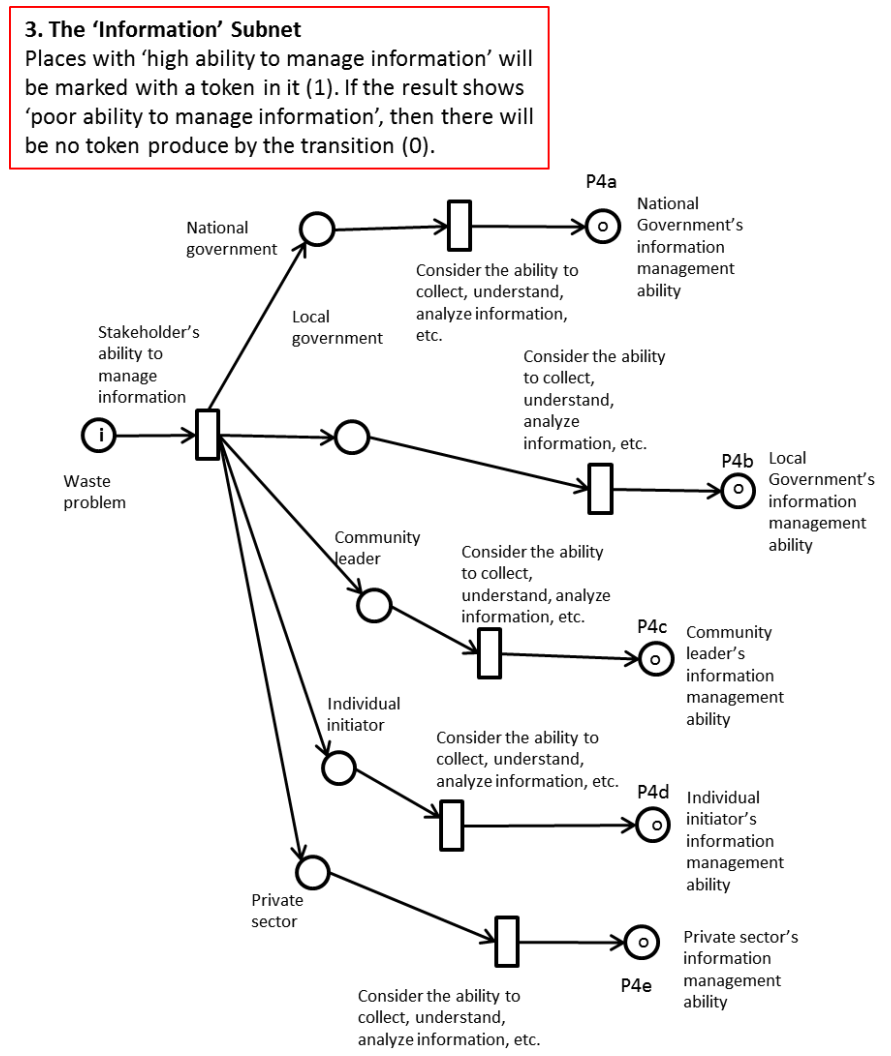

Figure A4. The "Information" Subnet.

\section{References}

1. International Council for Science (ICSU) and International Social Science Council (ISSC). Review of Targets for the Sustainable Development Goals: The Science Perspective; ICSU: Paris, France, 2015.

2. Scheer, H. Energy Autonomy: The Economic, Social and Technological Case for Renewable Energy, 2nd ed.; Earthscan: London, UK, 2007; Volume 41.

3. Malone, T.W. Is Empowerment Just a Fad? Control, Decision Making, and IT. MIT Sloan Manag. Rev. 1997, 38, 22-35.

4. Malone, T.W. The Future of Work: How the New Order of Business Will Shape Your Organizations, Your Management Style, and Your Life; Harvard Business School Press: Boston, MA, USA, 2004.

5. Malone, T.W.; Laubacher, R.; Scott Morton, M.S. Inventing the Organizations of the 21st Century; MIT Press: Cambridge, MA, USA, 2003.

6. Kralewski, D. Bottom-up decentralized approach to innovation strategy. In Proceedings of the 1st Workshop on New Generation Enterprise and Business Innovation Systems (NGEBIS-2012), Gdansk, Poland, 26 June 2012; Missikoff, M., Smith, F., Eds.; CEUR-WS: Gdansk, Poland, 2012; Volume 864, pp. 55-61.

7. Piper, M. Autonomy: Normative. Available online: http://www.iep.utm.edu/aut-norm (accessed on 20 November 2015).

8. Dryden, J. Autonomy. Available online: http://www.iep.utm.edu/autonomy/ (accessed on 21 November 2015).

9. Prause-Stamm, J. Self-Directedness and Resoluteness: The Two Dimensions of Autonomy; The Humboldt University of Berlin: Berlin, Germany, 2013.

10. Korb, A. The Upward Spiral: Using Neuroscience to Reverse the Course of Depression, One Small Change at a Time; New Harbinger Publications, Inc.: Oakland, CA, USA, 2015.

11. Achor, S. The Happiness Advantage: The Seven Principles of Positive Psychology that Fuel Success and Performance at Work; Crown Business: New York, NY, USA, 2010.

12. Zaharia, P. Autonomy and decentralization: Current priorities in the local public administration management. USV Ann. Econ. Public Admin. 2011, 11, 288-292. 
13. Beard, V.A.; Miraftab, F.; Silver, C. Planning and Decentralization: Contested Spaces for Public Action in the Global South; Routledge: New York, NY, USA, 2008.

14. Mackenzie, C. Three dimensions of autonomy: A relational analysis. In Autonomy, Oppression, and Gender; Veltman, A., Piper, M., Eds.; Oxford University Press: Oxford, UK, 2014; pp. 15-41.

15. Di Paolo, E.A.; Iizuka, H. How (not) to model autonomous behaviour. Biosystems 2008, 91, $409-423$. [CrossRef] [PubMed]

16. Simon, H.A. The New Science of Management Decision; Harper and Brothers: New York, NY, USA, 1960.

17. Braunstein, D.N. Review of managerial decision making/model building for decision analysis. Acad. Manag. Rev. 1981, 6, 515-517.

18. Petrie, J.; Cohen, B.; Stewart, M. Decision support frameworks and metrics for sustainable development of minerals and metals. Clean Technol. Environ. Policy 2007, 9, 133-145. [CrossRef]

19. Montana, P.J.; Charnov, B.H. Management; Barron's Educational Series, Inc.: New York, NY, USA, 2000.

20. Sexton, K.; Marcus, A.F.; Easter, K.W.; Burkhardt, T.D. Better Environmental Decisions: Strategies for Governments, Businesses and Communities; Island Press: Washington, DC, USA, 1999.

21. Jollands, N.; Gasc, E.; Pasquier, S.B. Innovations in Multi-Level Governance for Energy Efficiency; IEA: Paris, France, 2009.

22. Organization for Economic Cooperation and Development. Cities, Climate Change and Multilevel Governance; OECD: Paris, France, 2009.

23. Bale, C.S.E.; Foxon, T.J.; Hannon, M.J.; Gale, W.F. Strategic energy planning within local authorities in the UK: A study of the city of Leeds. Energy Policy 2012, 48, 242-251. [CrossRef]

24. Bale, C.S.E.; Abuhussein, A.M.; Foxon, T.J.; Hannon, M.J.; Gale, W.F. Delivering national policy at the local level: The role for local authorities in the implementation of the UKs flagship Green Deal policy. In Proceedings of the International Sustainable Development Research Conference, Hull, UK, 24-26 June 2012.

25. Indonesia Ministry of Energy and Mineral Resources (Kementrian ESDM). Blueprint Pengelolaan Energi Nasional 2006-2025; Kementrian ESDM: Jakarta, Indonesia, 2006.

26. Bulkeley, H.; Kern, K. Local Government and the Governing of Climate Change in Germany and the UK. Urban Stud. 2006, 43, 2237-2259. [CrossRef]

27. Blanchet, T. Struggle over energy transition in Berlin: How do grassroots initiatives affect local energy policy-making? Energy Policy 2014, 78, 246-254. [CrossRef]

28. Pitt, D. Harnessing community energy: The keys to climate mitigation policy adoption in US municipalities. Local Environ. Int. J. Justice Sustain. 2010, 15, 717-729. [CrossRef]

29. St Denis, G.; Parker, P. Community energy planning in Canada: The role of renewable energy. Renew. Sustain. Energy Rev. 2009, 13, 2088-2095. [CrossRef]

30. Tozer, L. Community energy plans in Canadian cities: Success and barriers in implementation. Local Environ. Int. J. Justice Sustain. 2013, 18, 20-35. [CrossRef]

31. Jaccard, M.; Failing, L.; Berry, T. From equipment to infrastructure: Community energy management and greenhouse gas emission reduction. Energy Policy 1997, 25, 1065-1074. [CrossRef]

32. Walker, G.; Hunter, S.; Devine-Wright, P.; Evans, B.; Fay, H. Harnessing Community Energies: Explaining and Evaluating Community-Based Localism in Renewable Energy Policy in the UK. Glob. Environ. Polit. 2007, 7, 64-82. [CrossRef]

33. Seyfang, G.; Park, J.J.; Smith, A. A thousand flowers blooming? An examination of community energy in the UK. Energy Policy 2013, 61, 977-989. [CrossRef]

34. Seyfang, G.; Haxeltine, A. Growing grassroots innovations: Exploring the role of community-based initiatives in governing sustainable energy transitions. Environ. Plan. C Gov. Policy 2012, 30, 381-400. [CrossRef]

35. Walker, G.; Devine-Wright, P. Community renewable energy: What should it mean? Energy Policy 2008, 36, 497-500. [CrossRef]

36. Axsen, J.; Kurani, K.S. Social Influence, Consumer Behavior, and Low-Carbon Energy Transitions. Annu. Rev. Environ. Resour. 2012, 37, 311-340. [CrossRef]

37. Heiskanen, E.; Johnson, M.; Robinson, S.; Vadovics, E.; Saastamoinen, M. Low-carbon communities as a context for individual behavioural change. Energy Policy 2010, 38, 7586-7595. [CrossRef]

38. Moloney, S.; Strengers, Y. "Going Green"? The Limitations of Behaviour Change Programmes as a Policy Response to Escalating Resource Consumption. Environ. Policy Gov. 2014, 24, 94-107. [CrossRef] 
39. Naus, J.; Spaargaren, G.; van Vliet, B.J.M.; van der Horst, H.M. Smart grids, information flows and emerging domestic energy practices. Energy Policy 2014, 68, 436-446. [CrossRef]

40. Wolsink, M. The research agenda on social acceptance of distributed generation in smart grids: Renewable as common pool resources. Renew. Sustain. Energy Rev. 2012, 16, 822-835. [CrossRef]

41. Prilandita, N.; McLellan, B.C.; Tezuka, T. The Framework for Identifying Autonomous Decision-Making Process on Energy and Environmental Issues: The Case Studies in Indonesian Communities (Rukun Warga). Available online: http:/ / www.j-sustain.com (accessed on 4 January 2016).

42. Hillion, H.P. Performance Evaluation of Decision-Making Organizations Using Timed Petri Nets; Massachusetts Institute of Technology: Cambridge, MA, USA, 1986.

43. Shukla, A.; Robbi, A.D. A Petri net simulation tool. In Proceedings of the 1991 IEEE International Conference on Systems, Man, and Cybernetics, "Decision Aiding for Complex System", Charlottesville, VA, USA, 13-16 October 1991; pp. 361-366.

44. Bullers, W.I. A Tripartite Approach to Information Systems Development. Decis. Sci. 1991, 22, $120-135$. [CrossRef]

45. Wang, J. Petri nets for dynamic event-driven system modeling. In Handbook of Dynamic System Modeling; Fishwick, P., Ed.; CRC Press: Boca Raton, FL, USA, 2007; pp. 1-17.

46. Sileno, G.; Boer, A. Legal knowledge conveyed by narratives: Towards a representational model. In Proceedings of the Workshop on Computational Models of Narrative (CMN 2014), Quebec City, QC, Canada, 31 July-2 August 2014; pp. 182-191.

47. Balas, D.; Brom, C.; Abonyi, A.; Gemrot, J. Hierarchical petri nets for story plots featuring virtual humans. In Proceedings of the 4th Artificial Intelligence and Interactive Digital Entertainment Conference, Palo Alto, CA, USA, 22-24 October 2008; Association for the Advancement of Artificial Intelligence: Stanford, CA, USA, 2008; pp. 2-9.

48. Araújo, M.; Roque, L. Modeling games with petri nets. In Breaking New Ground: Innovation in Games, Play, Practice and Theory; Digital Games Research Association (DiGRA): London, UK, 2009.

49. Xie, N.; Duan, M.; Chinnam, R.B.; Li, A.; Xue, W. An energy modeling and evaluation approach for machine tools using generalized stochastic Petri Nets. J. Clean. Prod. 2015, 113, 523-531. [CrossRef]

50. Sava, A.; Adjallah, K.H.; Lagaza, H. Hybrid Petri nets for modeling and control of multi-source energy conversion systems. In Proceedings of the 2014 International Conference on Control, Decision and Information Technologies (CoDIT), Metz, France, 3-5 November 2014; pp. 516-521.

51. Kyriakarakos, G.; Dounis, A.I.; Arvanitis, K.G.; Papadakis, G. A fuzzy cognitive maps-petri nets energy management system for autonomous polygeneration microgrids. Appl. Soft Comput. 2012, 12, 3785-3797. [CrossRef]

52. Bat'a, R.; Obršálová, I.; Volek, J.; Jordão, T.C. Petri nets application for management of biodegradable components of municipal waste. WSEAS Trans. Environ. Dev. 2008, 4, 1057-1066.

53. Bat'a, R.; Kárník, J. Modeling of environmental effect of biofuels by Petri Nets. In Advances in Environment, Biotechnology and Biomedicine; WSEAS Press: Zlin, Czech Republic, 2012; pp. 69-74.

54. Zhou, M. Petri Nets in Flexible and Agile Automation; Kluwer Academic Publishers: New York, NY, USA, 1995.

55. Indonesia Ministry of Public Works. Best Practices of Solid Waste Management in Indonesia (in Bahasa Indonesia); Departemen Pekerjaan Umum: Jakarta, Indonesia, 2007.

56. Hidayat, M.; Tanuwidjaja, G. Proposal Revitalisasi Permukiman dan Sistem Lingkungan Kelurahan Cibangkong Bertumpu kepada Masyarakat; Green Impact Indonesia: Bandung, Indonesia, 2009.

57. Amir, E.; Hophmayer-Tokich, S.; Kurnani, T. Socio-Economic Considerations of Converting Food Waste into Biogas on a Household Level in Indonesia: The Case of the City of Bandung. Recycling 2015, 1, 61-88. [CrossRef]

58. Plous, S. The Psychology of Judgment and Decision Making; McGraw-Hill: New York, NY, USA, 1993.

59. Hufty, M. Investigating policy processes: The Governance Analytical Framework (GAF). In Research for Sustainable Development: Foundations, Experiences, and Perspectives; Wiesmann, U., Hurni, H., Eds.; Geographica Bernensia: Bern, Switzerland, 2011; pp. 403-424.

60. Ameriks, J.; Caplin, A.; Leahy, J.; Tyler, T. Measuring Self-Control Problems. Am. Econ. Rev. 2007, 97, $966-972$. [CrossRef]

61. Nicholson, N.; Audia, P.G.; Pillutla, M.M. The Blackwell Encyclopedia of Management: Organizational Behavior, 2nd ed.; Blackwell Publishing Ltd.: Oxford, UK, 2005. 
62. Schweizer-Ries, P. Energy sustainable communities: Environmental psychological investigations. Energy Policy 2008, 36, 4126-4135. [CrossRef]

63. Barr, S.; Gilg, A.; Shaw, G. Citizens, consumers and sustainability: (Re)Framing environmental practice in an age of climate change. Glob. Environ. Chang. 2011, 21, 1224-1233. [CrossRef]

64. Deci, E.; Ryan, R.M. Intrinsic Motivation and Self-Determination in Human Behavior, 1st ed.; Springer Science \& Business Media: New York, NY, USA, 1985.

65. Wittayapak, C.; Dearden, P. Decision-Making Arrangements in Community-Based Watershed Management in Northern Thailand. Soc. Nat. Resour. 1999, 12, 673-691.

66. Getimis, P.; Heinelt, H. Leadership and Community Involvement in the European Cities: Conditions of Success and/or Failure. Available online: http://www.sampac.nl/EUKN2015/www.eukn.org/ dsresourcefaad.pdf?objectid=148461 (accessed on 14 May 2015).

67. Fahmi, F.Z.; Prawira, M.I.; Hudalah, D.; Firman, T. Leadership and collaborative planning: The case of Surakarta, Indonesia. Plan. Theory 2015. [CrossRef]

68. Wenshun, W.; Xiaohua, L.; Hualong, L. Empirical Research of the Environmental Responsibility Affected on the Urban Residential Housing Energy Saving Investment Behavior. Energy Procedia 2011, 5, 991-997. [CrossRef]

69. Barr, S.; Gilg, A.; Shaw, G. "Helping People Make Better Choices": Exploring the behaviour change agenda for environmental sustainability. Appl. Geogr. 2011, 31, 712-720. [CrossRef]

70. Williams, G. Responsibility. Available online: http://www.iep.utm.edu/responsi/ (accessed on 30 January 2016).

71. Fransson, N.; Gärling, T. Environmental concern: Conceptual definitions, measurement methods, and research findings. J. Environ. Psychol. 1999, 19, 369-382. [CrossRef]

72. Bale, C.; McCullen, N.; Foxon, T.; Rucklidge, A.; Gale, W. Local Authority Interventions in the Domestic Sector and the Role of Social Networks: A Case Study from the City of Leeds. Available online: http:/ / opus.bath.ac.uk/33041 (accessed on 21 January 2016).

73. Bale, C.S.E.; McCullen, N.J.; Foxon, T.J.; Rucklidge, A.M.; Gale, W.F. Harnessing social networks for promoting adoption of energy technologies in the domestic sector. Energy Policy 2013, 63, 833-844. [CrossRef]

74. Seyfang, G.; Smith, A. Grassroots innovations for sustainable development: Towards a new research and policy agenda. Environ. Polit. 2007, 16, 584-603. [CrossRef]

75. Ritzer, G. The Blackwell Encyclopedia of Socology, 4th ed.; Blackwell Publishing Ltd.: Oxford, UK, 2009.

76. Innes, J.E.; Booher, D.E. Consensus Building and Complex Adaptive Systems. J. Am. Plan. Assoc. 1999, 65, 412-423. [CrossRef]

77. Innes, J.E.; Booher, D.E. Planning with Complexity: An Introduction to Collaborative Rationality for Public Policy, 1st ed.; Routledge: New York, NY, USA, 2010.

78. Peters, M.A. The Idea of Openness: Open Education and Education for Openness. Available online: http:/ / eepat.net/doku.php?id=open_education_and_education_for_openness (accessed on 30 January 2016).

79. Abrahamse, W.; Steg, L.; Vlek, C.; Rothengatter, T. A review of intervention studies aimed at household energy conservation. J. Environ. Psychol. 2005, 25, 273-291. [CrossRef]

80. Spaargaren, G.; Oosterveer, P. Citizen-Consumers as Agents of Change in Globalizing Modernity: The Case of Sustainable Consumption. Sustainability 2010, 2, 1887-1908. [CrossRef]

81. Booher, D.E.; Innes, J.E. Network Power in Collaborative Planning. J. Plan. Educ. Res. 2002, 21, 221-236. [CrossRef]

82. Amabile, T.M. Creativity in Context; Westview Press: Boulder, CO, USA, 1996.

83. De Vries, M.S. The rise and fall of decentralization: A comparative analysis of arguments and practices in European countries. Eur. J. Polit. Res. 2000, 38, 193-224. [CrossRef]

84. Monger, R.F. Managerial Decision Making with Technology, 1st ed.; Pergamon Press: New York, NY, USA, 1987.

85. Rogers, E.M. Diffusion of Innovations, 5th ed.; Simon and Schuster: New York, NY, USA, 2003.

86. Devine-Wright, P. Renewable Energy and the Public: From NIMBY to Participation; Earthscan: London, UK, 2011; Volume 32.

87. Hodson, M.; Marvin, S. Can cities shape socio-technical transitions and how would we know if they were? Res. Policy 2010, 39, 477-485. [CrossRef]

(C) 2016 by the authors; licensee MDPI, Basel, Switzerland. This article is an open access article distributed under the terms and conditions of the Creative Commons Attribution (CC-BY) license (http:/ / creativecommons.org/licenses/by/4.0/). 